\title{
Metabolic Syndrome in Obese and Normal Weight Myanmar Children
}

\author{
Khin Than Yee, ${ }^{1}$ Theingi Thwin, ${ }^{2}$ Ei Ei Khin, ${ }^{3}$ Ko Ko Zaw, ${ }^{4}$ Nwe Nwe Oo, ${ }^{1}$ Aye Myint Oo, ${ }^{5}$ \\ Lwin Zar Maw, ${ }^{1}$ May Thu Kyaw, ${ }^{1}$ Nwe Ni Aung ${ }^{1}$ \\ ${ }^{1}$ Biochemistry Research Division, Department of Medical Research (Lower Myanmar) \\ ${ }^{2}$ Nutrition Research Division, Department of Medical Research (Lower Myanmar) \\ ${ }^{3}$ Department of Pediatrics, University of Medicine (1), Yangon, Myanmar \\ ${ }^{4}$ Medical Statistics Division, Department of Medical Research (Lower Myanmar) \\ ${ }^{5}$ Blood Research Division, Department of Medical Research (Lower Myanmar)
}

\begin{abstract}
Objectives. To estimate the frequency of Metabolic Syndrome (MS in Myanmar obese children and to determine the risk factors associated with MS in obese children comparing with normal weight children.

Methodology. A cross-sectional study was conducted to compare the risk factors for metabolic syndrome between normal and obese children by using the pediatric definition for metabolic syndrome [International Diabetes Federation (IDF), 2007]. Twenty-three obese children (BMI, $\geq 97^{\text {th }}$ percentile) and 23 normal weight children (BMI, $<85^{\text {th }}$ percentile) aged 5-12 years were included in the study. Blood pressure, body weight, height, waist circumference (WC), fasting triglycerides, HDL-cholesterol, total cholesterol and glucose concentrations were determined.
\end{abstract}

Results. Based on the IDF pediatric criteria, 9 obese children (39.1\%) had metabolic syndrome while no normal weight child had metabolic syndrome. Ten (43.5\%) normal weight children and $3(13.0 \%)$ obese children had at least one risk factor for the metabolic syndrome. Central obesity (WC $\geq 90^{\text {th }}$ percentile for age and sex), the most common risk factor, was observed in 25 children (54.4\% of the total population).

Conclusion. This study highlights the need for early recognition of risk factors for metabolic syndrome in all children to halt the progression of type 2 diabetes and cardiovascular diseases (CVD) in later life.

Keywords: metabolic syndrome, risk factors, obese children

\section{INTRODUCTION}

The prevalence of obesity in children and adults has increased over several decades in many countries due to changes in lifestyle and nutritional behaviors. In Myanmar, according to the national survey in 2009, the prevalence of overweight and obesity were $25.38 \%$ and $6.8 \%$ in adults. Among children and adolescents aged 1019 years in Yangon, the prevalence of obesity was $7.6 \% .{ }^{1}$ It is known that one-third of obese children and $80 \%$ of obese adolescents remain obese when they reach adulthood. ${ }^{2}$

Metabolic syndrome (MS) is recognized as the clustering of risk factors of obesity, insulin resistance, dyslipidemia and hypertension with the subsequent development of CVD and type 2 diabetes. ${ }^{3}$ Reaven described Syndrome X as the combination of hyperglycemia, hypertension and hyperuricemia and noted the relationship between systemic insulin resistance and the metabolic syndrome in 1988. ${ }^{4}$ The World Health Organization (WHO) in 1988, the

\section{ISSN 0857-1074}

Printed in the Philippines

Copyright $(\subset) 2013$ by the JAFES

Received February 19, 2013. Accepted April 23, 2013.

The paper has been presented in the Myanmar Health Research Congress (2012) on 8th January, 2013 in Department of Medical Research (Lower Myanmar), Yangon, Myanmar.
National Cholesterol Education Program (NCEP) in 2001 and the International Diabetes Federation (IDF) in 2005 have further defined the criteria for the syndrome. ${ }^{5-7}$ The most commonly applied criteria recommended for children in comparative studies are the modified WHO, NCEP using childhood cut-off values, Cook and the IDF consensus criteria. The IDF (2007) recently proposed a definition of MS used for children and adolescents. ${ }^{8}$ It has been divided according to the age groups: 6 to $<10,10$ to $<16$ and $\geq 16$ years. In all three groups, abdominal obesity is the essential condition for diagnosis of the MS. It suggests that below 10 years old, MS should not be diagnosed but further measurements should be made if there is a family history of the syndrome, type 2 diabetes, dyslipidemia, CVD, hypertension, and/or obesity. A strong message for weight reduction should be delivered for those with abdominal obesity. For children aged 10 to $<16$ years, a diagnosis of MS can be made with abdominal obesity and the presence of two or more of the other components (elevated triglyceride, low HDL-cholesterol, high blood pressure and elevated plasma glucose). For

Corresponding author: Khin Than Yee, MD

Research Officer

Biochemistry Research Division

Department of Medical Research (Lower Myanmar)

No. 5, Ziwaka Road, Dagon Township, Yangon, Myanamar

Tel. No.: (Office) 095-01-375447/375457/37459 Ext. 306

Fax No.: (Office) 095-01-251514

E-mail: khinthanyee@gmail.com 
adolescents aged $\geq 16$ years, the IDF adult criteria can be used including $90^{\text {th }}$ percentile cut-off for WC and $<40$ $\mathrm{mg} / \mathrm{dl}$ of HDL for both sexes.

Children with the cluster of factors defined as pediatric metabolic syndrome were significantly more likely to have CVD 25 years later as adults, compared with their peers. ${ }^{9}$ The aims of the study were to estimate the frequency of MS in Myanmar obese children and to determine the risk factors associated with MS in obese children comparing with normal weight children.

\section{METHODOLOGY}

\section{Study population}

The study population included a total of 46 children aged 5-12 years ( 25 boys and 21 girls). Twenty three obese children (BMI, $\geq 97^{\text {th }}$ percentile) from the Obesity Clinic, Yangon Child Hospital and 23 age-and gender-matched controls (BMI, between $15^{\text {th }}$ to $85^{\text {th }}$ percentile) were recruited as comparison groups using the WHO (2007) growth reference for children 5-19 years of age. Informed consent was obtained from the guardian of each child and the study was reviewed and approved by the Ethical Committee of Department of Medical Research.

\section{General examination and anthropometry}

Body weight and height were measured to the nearest 0.1 $\mathrm{kg}$ and $0.1 \mathrm{~cm}$ respectively, using standardized equipment and procedures. ${ }^{10}$ Body mass index (BMI) was calculated from the formula: weight $(\mathrm{kg})$ divided by height $(\mathrm{m})$ to the power of two (weight/height ${ }^{2}$ ). The waist circumference (WC) measurement was measured to the nearest $0.1 \mathrm{~cm}$, at a level parallel to the floor, midpoint between the top of the iliac crest and the lower margin of the last palpable rib in the mid-axillary line. ${ }^{11}$ The WC percentiles were determined based upon from the age- and gender-specific WC percentiles chart of Hong Kong Chinese children. ${ }^{12}$ The children with $W C \geq 90^{\text {th }}$ percentile for age and sex were recorded as having central obesity. Systolic and diastolic blood pressures were measured using a standardized sphygmomanometer in lying position. Hypertension was defined as systolic or diastolic blood pressure $\geq 130$ or $\geq 85 \mathrm{mmHg}$, respectively.

\section{Laboratory procedures}

Blood samples were obtained after a 10- to 12-hour fast for determination of plasma glucose, cholesterol, triglyceride, and lipoprotein fraction concentrations. Plasma glucose was obtained by the glucose oxidase technique and serum lipids were measured by enzymatic colorimetric methods.

\section{Definition of the Metabolic Syndrome}

All participants were defined as having MS based on the pediatric definition of IDF (2007). An individual has MS if
WC was $\geq 90^{\text {th }}$ percentile and at least two of the following components were above or under a single cut-off point: triglyceride $\geq 150 \mathrm{mg} / \mathrm{dl}$, HDL-cholesterol< $40 \mathrm{mg} / \mathrm{dl}$, fasting plasma glucose $\geq 100 \mathrm{mg} / \mathrm{dl}$, systolic or diastolic blood pressure (BP) $\geq 130$ or $\geq 85 \mathrm{mmHg}$, respectively.

\section{Statistical analyses}

Statistical analysis was performed using Stata Version 11. Means and standard deviation were used to summarize variables. Between the two groups, differences in general characteristics, metabolic profiles and risk of MS were tested using Student-t test and Fisher's exact test. Bivariate correlation analysis was performed using the Spearman correlation. The level of significant was set at $\mathrm{p}<0.05$.

\section{RESULTS}

Table 1 shows the physical and clinical characteristics of the participants in both groups. The mean age of obese children was $8.9 \pm 1.98$ years and the mean age of the control group was $9.99 \pm 2.02$ years. Despite the higher mean height of the obese children $(134.08 \pm 11.71 \mathrm{~cm})$, they were not significantly taller than the normal weight children who had a mean height of $132.13 \pm 12.83 \mathrm{~cm}$. However, the obese group had significantly higher values for weight, BMI and WC compared to the normal weight group $(\mathrm{p}<0.05)$.

\begin{tabular}{|c|c|c|c|}
\hline Variables & Obese $(n=23)$ & Normal $(n=23)$ & $p$ value \\
\hline \multicolumn{4}{|l|}{ Physical characteristics } \\
\hline Age (years) & $8.9 \pm 1.98$ & $9.99 \pm 2.02$ & 0.0721 \\
\hline Weight (kg) & $49.95 \pm 14.23^{*}$ & $27.96 \pm 6.70$ & 0.0000 \\
\hline Height (cm) & $134.08 \pm 11.71$ & $132.13 \pm 12.83$ & 0.5918 \\
\hline $\operatorname{BMI}\left(\mathrm{kg} / \mathrm{m}^{2}\right)$ & $27.35 \pm 5.18^{*}$ & $15.87 \pm 1.37$ & 0.0000 \\
\hline Waist circumference $(\mathrm{cm})$ & $85.39 \pm 12.63^{*}$ & $58.62 \pm 5.09$ & 0.0000 \\
\hline Systolic BP (mm Hg) & $107.23 \pm 17.53^{*}$ & $91.52 \pm 9.59$ & 0.0005 \\
\hline Diastolic BP $(\mathrm{mm} \mathrm{Hg})$ & $67.05 \pm 16.45^{\star}$ & $54.35 \pm 9.08$ & 0.0024 \\
\hline \multicolumn{4}{|l|}{ Biochemical parameters } \\
\hline $\begin{array}{l}\text { Fasting plasma } \\
\text { glucose }(\mathrm{mg} / \mathrm{dl})\end{array}$ & $78.35 \pm 15.38$ & $82.98 \pm 9.79$ & 0.2301 \\
\hline Total cholesterol (mg/dl) & $154.89 \pm 48.25^{*}$ & $127.97 \pm 29.52$ & 0.0274 \\
\hline LDL-cholesterol (mg/dl) & $94.64 \pm 46.88^{*}$ & $69.08 \pm 30.36$ & 0.0335 \\
\hline HDL-cholesterol (mg/dl) & $36.97 \pm 14.97$ & $44.02 \pm 8.89$ & 0.0587 \\
\hline Triglycerides (mg/dl) & $107.00 \pm 47.93^{*}$ & $68.81 \pm 27.62$ & 0.0019 \\
\hline
\end{tabular}

Based on clinical profiles, the obese group had significantly higher systolic blood pressure (SBP), diastolic blood pressure (DBP), total cholesterol, LDL-cholesterol and triglyceride levels compared to the normal weight group $(\mathrm{p}<0.05)$. Although the mean HDL-cholesterol and fasting glucose levels were lower in the obese group, there was no statistically significant difference between the two groups.

\section{The prevalence of MS}

According to the IDF pediatric definition, the overall prevalence of MS in the study population was $19.6 \%$. According to weight category, the prevalence of MS was 
$39.1 \%$ in obese children compared to $0 \%$ in normal weight children (Table 2).

\begin{tabular}{|c|c|c|c|}
\hline Components & $\begin{array}{l}\text { Obese } \\
(\mathrm{n}=23)\end{array}$ & $\begin{array}{l}\text { Normal } \\
(n=23)\end{array}$ & $\begin{array}{l}\text { Overall } \\
(n=46)\end{array}$ \\
\hline \multicolumn{4}{|c|}{ Individual components of metabolic syndrome } \\
\hline Large WC ( $\geq 90^{\text {th }}$ percentile) & $23(100.0)$ & $2(8.7)$ & $25(54.4)$ \\
\hline $\begin{array}{l}\text { High blood pressure } \\
(\mathrm{SBP} \geq 130 / \mathrm{DBP} \geq 85 \mathrm{~mm} \mathrm{Hg})\end{array}$ & $4(17.4)$ & 0 & $4(8.7)$ \\
\hline $\begin{array}{l}\text { High fasting blood sugar } \\
(\geq 100 \mathrm{mg} / \mathrm{dl})\end{array}$ & $1(4.3)$ & $1(4.3)$ & $2(4.3)$ \\
\hline $\begin{array}{l}\text { High triglyceride level } \\
(\geq 150 \mathrm{mg} / \mathrm{dl})\end{array}$ & $6(26.1)$ & 0 & $6(13.0)$ \\
\hline $\begin{array}{l}\text { Low HDL-cholesterol level } \\
(<40 \mathrm{mg} / \mathrm{dl})\end{array}$ & 19 (82.6) & $9(39.1)$ & $28(60.9)$ \\
\hline \multicolumn{4}{|c|}{ Pattern of risk factor clustering } \\
\hline None & 0 & $12(52.2)$ & $12(26.1)$ \\
\hline One risk factor only & $3(13.0)$ & $10(43.5)$ & $13(28.3)$ \\
\hline Two risk factors & $11(47.8)$ & $1(4.3)$ & $12(26.1)$ \\
\hline Three risk factors & $8(34.8)$ & 0 & $8(17.4)$ \\
\hline Four risk factors & $1(4.3)$ & 0 & $1(2.2)$ \\
\hline Five risk factors & 0 & 0 & 0 \\
\hline
\end{tabular}

\section{The prevalence of individual metabolic abnormalities}

Among the individual components of MS, large WC was the most common risk factor in the present study population. All obese children had central obesity, whereas 2 normal weight girls were centrally obese. This was followed by low HDL-cholesterol (82.6\%), high triglyceride level $(26.1 \%)$, high blood pressure $(17.4 \%)$ and high fasting blood sugar $(4.3 \%)$ in obese children. Unexpectedly, risk factors like low HDL-cholesterol $(39.1 \%)$ and high fasting blood sugar $(4.3 \%)$ were found in normal weight children (Table 2).

More than half of the normal weight children (52.2\%) did not have any risk factor of MS. However, all the obese children have at least one factor of MS but none of the children had all five components of MS (Table 2).

\section{DISCUSSION}

The overall prevalence of MS in the present clinic-based study population was $19.6 \%$ based on the IDF pediatric definition (2007). It is similar to that reported in children aged 6-11 years in Japan (14.5\%) and 7-17 year-old children in a French study (15.9\%). ${ }^{13-14}$ The overall prevalence of MS is diverse in different countries because of the different criteria used. The prevalence is low in 8-10 year-old Malaysian children (1.3\%), and is around 5-5.6\% in 6-11 year-old US children. ${ }^{15-17}$ Although variability existed between studies, the strikingly higher prevalence of MS among obese children and adolescents was found in many studies (30-38.8\%) similar to the present study $(39.1 \%) \cdot{ }^{18-22}$

Among obese children, abdominal obesity (increased WC) was the most prevalent component $(100 \%)$, followed by low HDL-cholesterol (82.6\%), high triglyceride (26.1\%), elevated blood pressure (17.4\%) and impaired fasting plasma glucose $(4.3 \%)$. The distribution of risk factors seen in our study was consistent with those in Malaysian obese children: highest WC (84.1\%) followed by low HDLcholesterol (19.7\%), increased triglyceride level (12.5\%), abnormal blood pressure $(6.3 \%)$, and high fasting glucose level (5.8\%). ${ }^{23}$ Esmailzadeh et al., reported that low HDLcholesterol was the most frequent while the least frequent was impaired fasting blood glucose. ${ }^{24}$ Decrease in HDLcholesterol level in obese children may be due to the rapid clearance from the circulation. Weight gain, especially if visceral fat increases, can in turn increase triglyceride lipolysis that will elevate free fatty acid levels. In the circulation, the triglyceride-rich VLDL will exchange triglycerides with cholesterol esters in HDL, resulting in triglyceride-rich and low cholesterol ester HDL plasma. This type of HDL is more easily catabolized by the kidney resulting in decreased HDL levels. ${ }^{25}$

The abnormal glucose homeostasis has a wide range and can progress from insulin resistance to diabetes. ${ }^{26} \mathrm{~A}$ longer duration of obesity may be required for the development of impaired glucose tolerance and type 2 diabetes. ${ }^{21}$

The BMI showed a significant positive relationship with WC $(r=0.677, p<0.001)$ and SBP $(r=0.469, p<0.05)$ in normal weight children and also with WC $(\mathrm{r}=0.594, \mathrm{p}<0.01)$, SBP $(\mathrm{r}=0.640, \mathrm{p}<0.01)$ and DBP $(\mathrm{r}=0.600, \mathrm{p}<0.01)$ in obese children. However, the WC showed a significant relationship with SBP $(\mathrm{r}=0.553, \mathrm{p}<0.01)$ and DBP $(\mathrm{r}=0.548$, $\mathrm{p}<0.01$ ) in obese children (Figure 1). Maffeis et al., proved that waist circumference showed a better correlation with SBP and DBP ( $r=0.45$ and 0.39 , respectively; $\mathrm{p}<0.01$ )in obese prepubertal children than the total sample population. ${ }^{27}$ Moreover, Lee et al., supported that WC should be included in the evaluation of childhood obesity along with BMI percentile to identify those at increased health risks due to excess abdominal fat. ${ }^{28}$ Therefore, WC is a sensitive marker of cardiovascular risk in identifying obese children at higher metabolic risk.

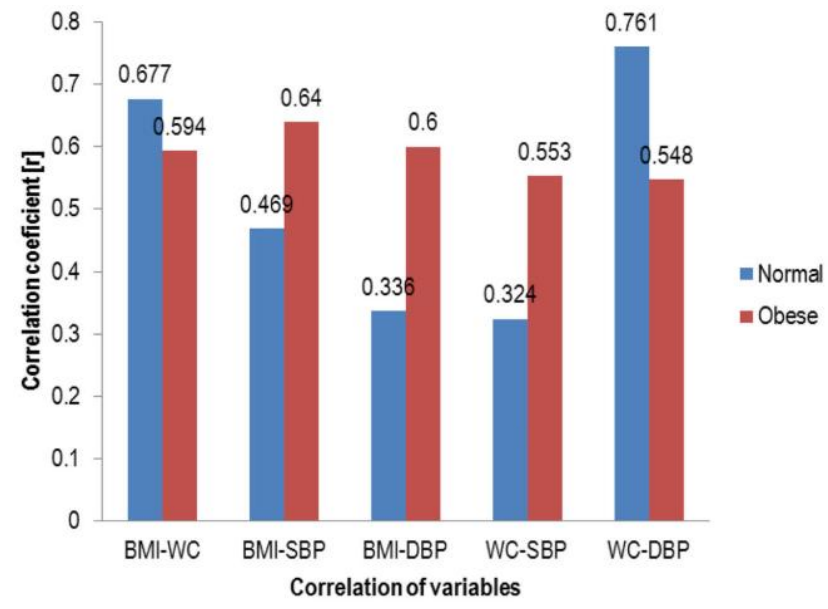

Figure 1. Correlation coefficient between variables, body mass index (BMI), waist circumference (WC), systolic blood pressure (SBP) and diastolic blood pressure (DBP) by weight category. 
However, there are no age-, gender- and ethnic-specific WC standards for Asian children, with the exception of the values based on a database of Hong Kong children and one from Malaysia. 12,29,30 Accordingly, it would be extremely useful to develop a WC cut-off point for each country so that meaningful comparisons could be made.

This study is not without its limitations. We did not include the family history of the children as well as their physical activity and dietary pattern. There is a positive relationship between the different components of MS with obesity, family history of hypertension, diabetes mellitus and CVD. ${ }^{31-32}$ Moreover, the risk of MS was 2.4 times higher in children with a family history of diabetes, hypercholesterolemia, high blood pressure or cardiovascular disease. ${ }^{15}$ Another limitation is the small sample size of the present study. A large sample size including non-urban samples is recommended in future studies to get a more representative study population.

\section{CONCLUSION}

The present study reveals that $39.1 \%$ of obese children in Myanmar have metabolic syndrome. None of them are free from the MS risks. This is in sharp contrast to $52.2 \%$ of the normal weight children who were free from all risk factors. However, the existence of one or more components of the metabolic syndrome risks in the normal weight children needs closer attention. There is evidence that clustered risk factors track strongly from childhood to young adulthood. Therefore, it is important to identify those children at greater risk for obesity-related ill health at an early stage to increase awareness and to have the opportunity to promote healthy lifestyle in children. This will reduce the death and disability in adulthood and help minimize the global burden of CVD and type 2 diabetes.

\section{Acknowledgements}

We thank all the team members, all participants and their parents. Special thanks to Dr. Kyaw Oo and Dr. Moh Moh Hlaing for their suggestions and contribution to this paper.

\section{References}

1. Latt TS, Ko K., Aye TT, Thidar A, Khin EE. A summary of the Myanmar clinical practice guidelines for the management of obesity. JAFES. 2011; 26 (2): 105-109.

2. Cinaz P, Bideci A. Pediatric Endocrinology, $1^{\text {st }}$ Ed, Turkish Pediatric Endocrinology and Auxology Society Publishments: Obesity. Ankara: Krenralkan Press, 2003.

3. Chen W, Srinivasan SR, Berenson GS. Path analysis of metabolic syndrome in black versus white children, adolescents and adults: The Bogalus Heart Study. Ann Epidemiol. 2008; 18(2): 85-91.

4. Reaven GM. Banting Lecture 1988: Role of insulin resistance in human disease. Diabetes. 1988; 37(12): 1595-1607.

5. Alberti KGMM, Zimmet PZ. Definition, diagnosis and classification of diabetes mellitus and its complications. Part I: Diagnosis and classification of diabetes mellitus provisional report of a WHO consultation. Diabet Med. 1998; 15(7): 539-553.

6. Expert Panel on detection, evaluation and treatment of high blood cholesterol in adults. Executive summary of the third report of the national cholesterol evaluation program (NCEP) Expert Panel on detection, evaluation, and treatment of high blood cholesterol in adults (Adult Treatment Panel III). JAMA. 2001, 285(19): 2486-2497.

7. Alberti KGMM, Zimmet PZ, Shaw JE. The metabolic syndrome- A new world-wide definition from the International Diabetes Federation Consensus. Lancet. 2005; 366(9491): 1059-1062.
8. Zimmet P, Alberti G, Kaufman F, et al. The metabolic syndrome in children and adolescents: The IDF consensus. Diabetes Voice. 2007; 52(4): 29-32.

9. Morrison JA, Friedman LA, Wang P, Glueck CJ. Metabolic syndrome in childhood predicts adult metabolic syndrome and type 2 diabetes mellitus 25 to 30 years later. J Pediatr. 2008; 152(2): 201-206.

10. Gibson RS. Principles of Nutritional Assessment. Oxford: Oxford University Press, 1990

11. World Health Organization. Waist circumference and waist-hip ratio: Report of a WHO expert consultation, Geneva, 8-11 December 2008. WHO, 2011.

12. Sung RYT, So H-K, Choi K-C, et al. Waist circumference and waist-toheight ratio of Hong Kong Chinese children. BMC Public Health. 2008; 8: 324.

13. Yoshinaga M, Tanaka S, Shimago A, et al. Metabolic syndrome in overweight and obese Japanese children. Obes Res. 2005; 13(7): 1135-1139.

14. Druet C, Dabbast M, Baltakse V, et al. Insulin resistance and the metabolic syndrome in obese French children. Clin Endocrinol. 2006; 64(6): 672-678.

15. Quah YV, PohBK.,Ismail MN. Metabolic syndrome based on IDF criteria in a sample of normal weight and obese school children. Mal J Nutr. 2010; 16(2): 207-217.

16. Dubose KD, Stewart EE, Charbonneau SR, Mayo MS, Donnelly JE. Prevalence of the metabolic syndrome in elementary school children. Acta Pediatr. 2006; 95(8): 1005-1011.

17. Braunschweig $\mathrm{CL}$, Gomez $\mathrm{S}$, Liang $\mathrm{H}$, et al. Obesity and risk factors for the metabolic syndrome among low-income, urban, African-American school children: The rule rather than the exception? Am J Clin Nutr. 2005; 81(5): 970-975.

18. Cruz ML, Weigensberg MJ, Haung TTK, et al. The metabolic syndrome in overweight Hispanic youth and the role of insulin resistance. J Clin Endocrinol Metab. 2004; 89(1): 108-113.

19. Viner RM, Segal TY, Lichtarowicz-Krynska E, Hindmarsh P. Prevalence of the insulin resistance syndrome in obesity. Arch Dis Child. 2005; 90(1): 1014.

20. Caceres M, Teran CG, Rodriguez S, Medina M. Prevalence of insulin resistance and its association with metabolic syndrome criteria among Bolivian children and adolescents with obesity. BMC Pediatr. August 12, 2008; 8:31.

21. Sen Y, Kandemir N, Alikasifoglu A, Gonc N, Ozon A. Prevalence and risk factors of metabolic syndrome in obese children and adolescents: The role of the severity of obesity. Eur J Pediatr.2008; 167(10): 1183-1189.

22. Cizmecioglu FM, Hatun S, Kalaca S. Metabolic syndrome in obese Turkish children and adolescents: comparison of two diagnostic models. Turk J Pediatr. 2008; 50(4): 359-365.

23. Wee BS, Poh BK, Bulgiba A, et al. Risk of metabolic syndrome among children living in metropolitan Kuala Lumpur: A case control study. BMC Public Health.2011; 11: 333.

24. Esmailzadeh A, Mirmiran P, Etemandi A, Azizi F. High prevalence of the metabolic syndrome in Iranian adolescents. Obesity. 2006; 14(3): 377-382.

25. Adam JMF.Metaboliksindrom. Bandung: Medical School, Padjajaran University, 2006.

26. Saad R, Gungor N, Arslanian S. Progression from normal glucose tolerance to type 2 diabetes in young girls: Longitudinal changes in insulin sensitivity and secretion assessed by the clamp technique and surrogate estimates. Pediatr Diabetes. 2005; 6(2): 95-99.

27. Maffeis C, Pietrobelli A, Grezzani A, Provera S, Tato L. Waist circumference and cardiovascular risk factors in prepubertal children. Obes Res. 2001; 9(3): 179-187.

28. Lee S, Bacha I, Arslanian SA. Waist circumference, blood pressure, and lipid components of the metabolic syndrome. J Pediatr. 2006; 149(6): 809816.

29. Liu A, Hills AP, Hu X, et al. Waist circumference cut-off values for the prediction of cardiovascular risk factors clustering in Chinese school-aged children: A cross-sectional study. BMC Public Health. 2010; 10: 82.

30. Poh BK, Jannah AN, Chong LK, et al. Waist circumference percentile curves for Malaysian children and adolescents aged 6.0-16.9 years. Int J Pediatr Obes. 2011; 6(3-4): 229-235.

31. Castillo EH, Borges G, Talavera JO, et al. Body mass index and the prevalence of metabolic syndrome among children and adolescents in two Mexican population. J Adolesc Health. 2007; 40(6): 521-526.

32. Kelishadi R, Gouya MM, Adeli K, et al. Factors associated with the metabolic syndrome in a national sample of youths: CASPIAN study. Nutr Metab Cardiovasc Dis. 2008; 18(7): 461-470. 